\title{
AUTOESTIMA DE MULHERES E HOMENS COM DOENÇA FALCIFORME: APLICAÇÃO DA ESCALA DE ROSENBERG
}

\author{
Luana Santana Brito ${ }^{1}$; Evanilda Souza de Santana Carvalho ${ }^{2}$ \\ 1. Bolsista PIBIC/CNPq-AF, Graduanda em Enfermagem, Universidade Estadual de Feira de \\ Santana, e-mail: luanasbrito@ hotmail.com \\ 2. Orientador, Departamento de Saúde, Universidade Estadual de Feira de Santana, e-mail: \\ evasscarvalho@yahoo.com.br
}

PALAVRAS-CHAVE:

Doença Falciforme; Autoestima; Enfermagem

\section{INTRODUÇÃO}

As pessoas com Doença Falciforme (DF) padecem com as diversas consequências dos danos promovidos pela doença a exemplo de: infecções, crises álgicas, acidente vascular cerebral, úlceras crônicas de perna e outras urgências significativas, que, invariavelmente, aumentam o número de hospitalizações e diminuem as horas dispensadas à escola e às demais atividades produtivas (LEVENSON, 2008). Manifestações psicológicas freqüentes como ansiedade, depressão, e perda da autoestima estão relacionadas à natureza crônica e fatal da doença e se intensificam frente às repetidas internações (THOMPSON; GUSTAFSON, 1998).

De acordo com Dini, Quaresma e Ferreira (2004), a autoestima é um componente da qualidade de vida e é definida como sentimento, apreço e consideração que uma pessoa tem por si própria, ou seja, quanto ela gosta de si, como ela se vê e o que pensa sobre ela mesma. A mensuração da autoestima tem sido mundialmente realizada por meio da Escala de Autoestima de Rosenberg - EAR (Rosenberg, 1965), a referida escala é descrita como um instrumento unidimensional com capacidade para classificar o nível de autoestima em baixo, médio e alto. (SBICIGO, BANDEIRA, DELL'AGLIO, 2010).

Diante disso, o presente estudo se justifica através da necessidade de avaliar a autoestima de mulheres e homens com doença falciforme, também na tentativa de que o estudo possa fornecer informações aos profissionais de Enfermagem e de saúde que contribuam para a adoção de atitudes comprometidas, buscando melhorar a assistência a dessas pessoas adoecidas que necessitam de cuidados diferenciados. Este estudo tem como objetivo avaliar o nível de autoestima de mulheres com doença falciforme com a aplicação da Escala de Autoestima de Rosenberg.

\section{MATERIAIS E MÉTODOS}

Pretende-se desenvolver um estudo quantitativo, transversal, do tipo exploratório descritivo. O cenário elegido para o desenvolvimento do estudo foi no Centro de Atenção à pessoas com DF situado no Centro Social Urbano (CSU) em Feira de Santana/BA. Participaram do estudo mulheres e homens com diagnóstico de doença falciforme. Os critérios de inclusão da pesquisa são: ter 18 anos ou mais, de ambos os sexos e ter diagnóstico de doença falciforme. Não foram adotados critérios de exclusão. A coleta de dados foi realizada através da aplicação de dois questionários: o primeiro sócio-econômico e demográfico do participante; o segundo conta com a aplicação da Escala de Autoestima de Rosenberg (versão brasileira, traduzida e culturalmente adaptada) (DINI; QUARESMA; FERREIRA, 2004). A autoestima do indivíduo é classificada em três níveis: alta, média e baixa autoestima. A técnica utilizada para a análise dos dados foi a estatística descritiva e 
inferencial. Os dados foram tratados e analisados por meio do Microsoft Excel 7 e apresentados a forma de tabelas e gráficos.

\section{RESULTADOS ALCANÇADOS}

No concernente à variável contínua (idade) realizou-se o cálculo da média, encontrando-se entre os participantes do estudo $(\mathrm{N}=10)$ uma média de idade de 39 anos. Com relação às variáveis qualitativas (sexo, escolaridade, etnia/cor, religião e ocupação): 60 \% (6) dos participantes eram do sexo masculino e $40 \%$ (4) do sexo feminino; 6 (60\%) participantes possuíam ensino fundamental incompleto, um (10\%) possuía ensino médio incompleto, um (10\%) possuía ensino médio completo, um (10\%) possuía ensino superior incompleto e um (10\%) possuía ensino superior completo; Quanto à etnia/cor, $40 \%$ declararam ser de cor preta, $40 \%$ se declararam cor parda, $10 \%$ se declarou amarela e $10 \%$ se declarou indígena; Quanto a prática religiosa, 08 participantes do estudo $(80 \%)$ revelaram o protestantismo, seguido do catolicismo (20\%). Quanto à ocupação profissional, 09 participantes $(90 \%)$ encontravam-se desempregados, ou seja, apenas um participante possuía ocupação remunerada.

As pontuações individuais obtidas a partir da aplicação da Escala de Rosenberg no que se refere aos dados relacionados à autoestima demonstraram variação de 23 a 35 pontos, cuja pontuação média do grupo foi 26,9 pontos, como pode ser observado na Tabela 1 .

Tabela 1. Distribuição dos participantes segundo as pontuações individuais referentes às dimensões da Escala de Autoestima de Rosenberg. Feira de Santana, BA, Brasil, 2017. n= 10

Dimensões da Escala

Amostra $(\mathrm{N}=10)$

1. Acho que sou uma pessoa digna de estima, pelo menos a mesma que os demais

2. Acho que tenho muitas boas qualidades

3. Tenho tendência a sentir que sou um fracasso em tudo

4. Sou capaz de fazer as coisas tão bem, como a maioria das outras pessoas

5. Acho que não tenho muitos motivos para me orgulhar de mim mesma/o

6. Tenho uma atitude positiva perante mim mesma/o

7. No geral estou satisfeita/o comigo mesma/o

8. Gostaria de ter mais respeito por mim mesma/o

9. Às vezes sinto-me realmente uma pessoa inútil

10. Às vezes penso que não sou grande coisa TOTAL

Média amostra $=\mathbf{2 6 , 9}$
Pontuações individuais da amostra (N = 10) 
A escala de auto-estima Rosenberg consiste em 10 perguntas com uma escala de 1 a 4 pontos, os intervalos para determinar o nível de auto-estima são: 30 a 40 pontos: alto nível normal de auto-considerado de auto-estima; 26 a 29 pontos de auto-estima média, este nível indica que há problemas sérios surgem estima, no entanto melhor para melhorar, e menos de 25 pontos: baixa auto-estima, neste intervalo, há significativa estima problemas. Com relação à classificação da autoestima, pôde se constatar 50\% da amostra consiste de pacientes com autoestima baixa (Tabela 2), seguido de $30 \%$ com a autoestima alta e $20 \%$ com a autoestima média.

Tabela 2. Distribuição dos pacientes com Doença Falciforme, conforme a classificação da autoestima. Feira de Santana, BA, Brasil, 2017

\begin{tabular}{ccc}
\hline Classificação da autoestima & F & \% \\
\hline Autoestima alta (30-40 pontos) & 3 & 30 \\
Autoestima média (26-29 & & \\
pontos) & 2 & 20 \\
Autoestima baixa (<26 pontos) & 5 & 50 \\
\hline Total & 10 & 100 \\
\hline
\end{tabular}

O desemprego se faz presente na maioria dos participantes e pode propiciar o desencadeamento de problemas psicoemocionais, como a baixa autoestima e dificuldade nas relações interpessoais . Essa situação pode interferir na saúde mental e na qualidade de vida dos participantes, além de dificultar o acesso aos serviços de saúde e influenciar na realização de práticas de autocuidado adequadas.

Um estudo realizado por Franklin e Atkin (1986) revelou que o nível de desemprego para as pessoas com DF é muito maior do que para aquelas que não têm a doença. Isso se deve por que os pacientes com DF sofrem discriminação prejudicando seus acessos a oportunidades de emprego. Além disso, algumas complicações crônicas e crises dolorosas tornam os pacientes incapazes para o trabalho regular.

A baixa escolaridade tem influência na renda mensal, pela maior susceptibilidade a empregos informais (MARQUES et al., 2015). Com isso, conclui-se que o desemprego está relacionado a baixa escolaridade, ao estigma/preconceito e com a frequência de complicações e crises álgicas. No período escolar, o comparecimento as aulas se torna difícil, sendo provável que essas crianças tenham $50 \%$ mais faltas que outras crianças normais (GIL et al., 2003).

Um dos fatores que podem estar relacionados com a adesão do paciente com DF é a baixa autoestima. A baixa autoestima pode estar associada a um quadro depressivo, o que dificulta a adesão ao tratamento e pode afetar a qualidade de vida desses sujeitos adoecidos.

\section{CONCLUSÕES}

No que tange à autoestima, a maioria dos participantes apresentaram autoestima baixa. Através deste estudo, é possível concluir que a raça (predomínio entre negros), a baixa escolaridade e o desemprego estão correlacionados com a baixa autoestima. Dessa forma, enfatiza-se a necessidade do desenvolvimento de políticas públicas na saúde, na educação e nas condições econômicas desses pacientes com estratégias com o objetivo de melhorar o manejo e controle da doença. Este estudo apresentou limitações no que diz respeito à exaustão dos participantes do centro por participarem de muitas pesquisas, contribuindo assim para uma amostra reduzida. Recomenda-se a ampliação de pesquisas que avaliem a autoestima em 
pessoas com DF, com amostras populacionais mais representativas e que se estabeleça relação da autoestima com as diversas complicações da doença.

\section{REFERÊNCIAS}

DINI, G.M.; QUARESMA, M.R.; FERREIRA, L.M. Adaptação cultural e validação da versão brasileira da escala de auto-estima de Rosenberg. Rev Soc Bras Cir Plast. v. 19, n. 1, p. 41-52, 2004.

FRANKLIN, I. M.; ATKIN, K. Employment of persons with sickle-cell disease and sicklecell trait. Occup. Med., v. 36, p. 76-79, 1986.

GIL, K. M. et al. Daily stress and mood and their association with pain, healthcare use, and school activity in adolescents with sickle cell disease. Journal of Pediatric Psychology, Oxford, UK, v. 28, n. 5, p. 363-373, 2003.

LEVENSON, J.L. Psychiatric issues in adults with sickle cell disease. Primary Psychiatry. v. 15, n. 5, p.45-49, 2008.

ROSENBERG, M. Self concept and psychological well-being in adolescence. In: ROSENBERG, M. Society and the adolescent self-image. Princeton, NJ: Princeton University Press, 1965.

SBICIGO, J. B.; BANDEIRA, D. R.; DELL'AGLIO, D. D. Escala de Autoestima de Rosenberg. Psico-USF, v. 15, n. 3, p. 395-403, set./dez. 2010.

SBICIGO, J. B.; BANDEIRA, D. R.; DELL'AGLIO, D. D. Escala de Autoestima de Rosenberg (EAR): validade fatorial e consistência interna. PsicoUSF, v. 15, p. 395-403, 2010.

THOMPSON, R.J.; GUSTAFSON, K.E. Illness specific patterns of psychological adjustment and cognitive adaptational processes in children with cystic fibrosis and sickle cell disease. $\mathbf{J}$ Clin Psycol. v. 54, n. 1, p.121-128, 1998. 